\title{
Philosophy of education is still fascinating educationists: A biblio-appraisal from 1929 - 2019
}

\section{Zameer Hussain Baladi ${ }^{1}$, Saleh Ali Al Qarni², Tahira Yasmin³, Taimoor Ali ${ }^{4}$}

${ }^{1,2,3}$ King Saud Bin Abdulaziz University for Health Sciences, College of Applied Medical Sciences, Riyadh, Kingdom of Saudi Arabia. ${ }^{4}$ Final Year Student, Bachelor of Law and Litigation (LLB) Batch 15/Roll No. 70, Indus College of Law, Hyderabad Sindh, Pakistan.

Received: 1 Oct 2020; Received in revised form: 16 Nov 2020; Accepted: 25 Nov 2020; Available online: 03 Dec 2020 (C)2020 The Author(s). Published by The Shillonga Publication. This is an open access article under the CC BY license (https://creativecommons.org/licenses/by/4.0/).

\begin{abstract}
Purpose: This study design to explore the literature produced and published in journals indexed in the Scopus-Elsevier database in terms of educational philosophy.

Methods: The data acquired from the journals indexed in the Scopus-Elsevier database for analysis. This study divided into eight spells and covered 92 years to examine; year-wise, type of documents, primary classification of subjects, authors' contribution, an affiliation of the first author with country, and the statistical position of the journal from 1929 - 2019.

Results: Total 1587 different types of documents written by 2168; 1.3\% of authors with an average of 17.2 per annum. The data distributed in 10 categories published from 1929 - 2019. Research articles 1070; 67.4\%, book chapters 164; 10.3\%, and review articles 95; 6\% standing on top slots. Spell 2011 - 2019, published maximum research in every category. The majority of 1189; $75 \%$ articles written by the single or solo author, followed by 242; $15 \%$ two authors, the authors of 28; 1.7\% not traced. A total of 697 places published 1587 documents. Journal of Educational Theory 113; 7.1\%, Journal of Educational Philosophy and Theory 103; 6.4\%, Journal of Philosophy of Education 92; 5.8\%, and Journal of Studies in Philosophy and Education 75; 4.7\% provides maximum spaces in publications as on single entity. Social Sciences covered 1216, 77\% of the research productivity, and followed by Science and Technology subjects. The United States of America 589; $37.1 \%$, United Kingdom 318; 20\%, and Canada 80; 5\% got top three positions from the contribution of sixtyeight countries.

Conclusion: Philosophy of education has the power to move society towards wisdom, to clarify the beliefs, strengthen values, relevant to intellectual thoughts of person and community, increase visualization of the spectrum of science and technological education.
\end{abstract}

Keywords - Bibliometric, philosophy of education, Scopus-Elsevier database, process of learning.

\section{INTRODUCTION AND LITERATURE REVIEW}

Philosophy is not a word. It carries a wagon of thoughts and actions. The discipline of philosophy developed on the judgmental exercise up-on experience, when a person thinks about the existence of reality, knowledge about nature, personal concepts, and beliefs. Education is the process of learning from experiences, done by himself or herself, or by the other person's contribution in the shape of a story, skill, and competency transmitted to individually or community for the benefit of society. Early civilizations used symbols to convey their concepts in delivering knowledge as methodologies; Hieroglyph, Papyrus, Oracle bone script, Maya script, Vellum, Wax tablet, and Parchment used as 
communicational tools to preserve and transferred these activities. A person involved in these activities had experience and the command of expressions; we can presume that people know him as academics. Smeyers, P., Depaepe, M. (2020) explained that the network of academics share their belief and rational approaches behind the matters got attentions which addressed to the portion of a community and discipline of education in a more profound understanding.

In 2018, Thomas, A.M. (2018) agreed with the educational philosophy of Adam Smith's. He appreciated the words that "in Smith's view, education conceived broadly to include both the learning of 'wisdom' and 'moral sentiments,' as central to a prosperous or flourishing society." He passed the quote of Smith's position that "education for all is necessary to create a prosperous society". Very before Opaleke, J.S. (1998) highlighted the philosophy of education. He described that students learn an informal or casual way; it is the ultimate learning instruction goal. Jun, A., Collins, C.S. (2019) discussed the belief system, reflecting the local context and culture in higher education. They emphasized colleges' role and their interventions with purpose, approaches, and techniques to fulfill the mission and vision of education for societal growth. In contrast, Feldges, T. (2019) argued the transformation of philosophical knowledge as content-orientated learning with the provision of historical description because "everyday practice and general theories are shown as genuine philia optical problem to draw the line between legitimate efforts and illegitimate indoctrination."

Kizel, A (2019) supports Feldges in his ideas, examines, and discusses the perception of self-determination in children about a lesson providing knowledge and the link of philosophical inquiry. He found that self-determined learning facilitates children with critical, caring, creative thinking to cultivate social activism. Gereluk, D. (2019) came forward and suggested an excellent approach to understand the philosophy of education. In his views, "Problems-based approach to the philosophy of education may help to elucidate the relevance and applicability." He assured that "This approach allows students to immediately see the relevance of philosophy in their daily lives as teachers." We found Hallinger, P. et al. (2020) are very near the approach of Gereluk, D. (2019), and pointed out that the development and the use of simulations games in education for support in a specific topic, subject, or discipline. Their content analysis on 376 relevant Scopus/Google Scholarindexed documents favored transferring the appropriate ethics through this strategy. Li, J., et al. (2020) appreciated the services of the Scopus-Elsevier database for supporting the research community in terms of referencing and downloading with specific word, subject, discipline, institution, and country-wise distribution.

\section{DESIGN/METHODS/APPROACH}

This retrospective study examines the published documents on education philosophy as "Article title" in journals indexed with the Scopus-Elsevier database from 1929 - 2019 (92 years). Data distributed in eight spells accorded to years for scrutinizing; year-wise, type of documents, primary classification of subjects, authors' contribution, an affiliation of the first author with country, top ten key words, languages of the manuscript, and statistical position of journals.

\section{RESULTS}

Figure 1 and 2, and table 1, explains the terminology of data of 1587 documents, published on the philosophy of education in journals indexed with the Scopus-Elsevier database from 1929 - 2019 (92 years) with an average 17.2 documents per annum and a maximum 87 and minimum 1 document. Table 1 reveals the breakdown of records in eight spells. Articles got the first slot in every period and produced 1070; 68\% documents. Mustapha, O. A et al. (2020) evaluate five main structures; introduction of the topic, methods, results of questionnaires, discussion, and conclusions fulfill the terms and conditions of any discipline pertained the essence of articles. [13] Followed by book chapters 164; $10.3 \%$, and review articles $95 ; 6 \%$ out of 1587 documents. 
Figure 1: Research published in Scopus-Elsevier database on philosophy of education from 1929 - 2019
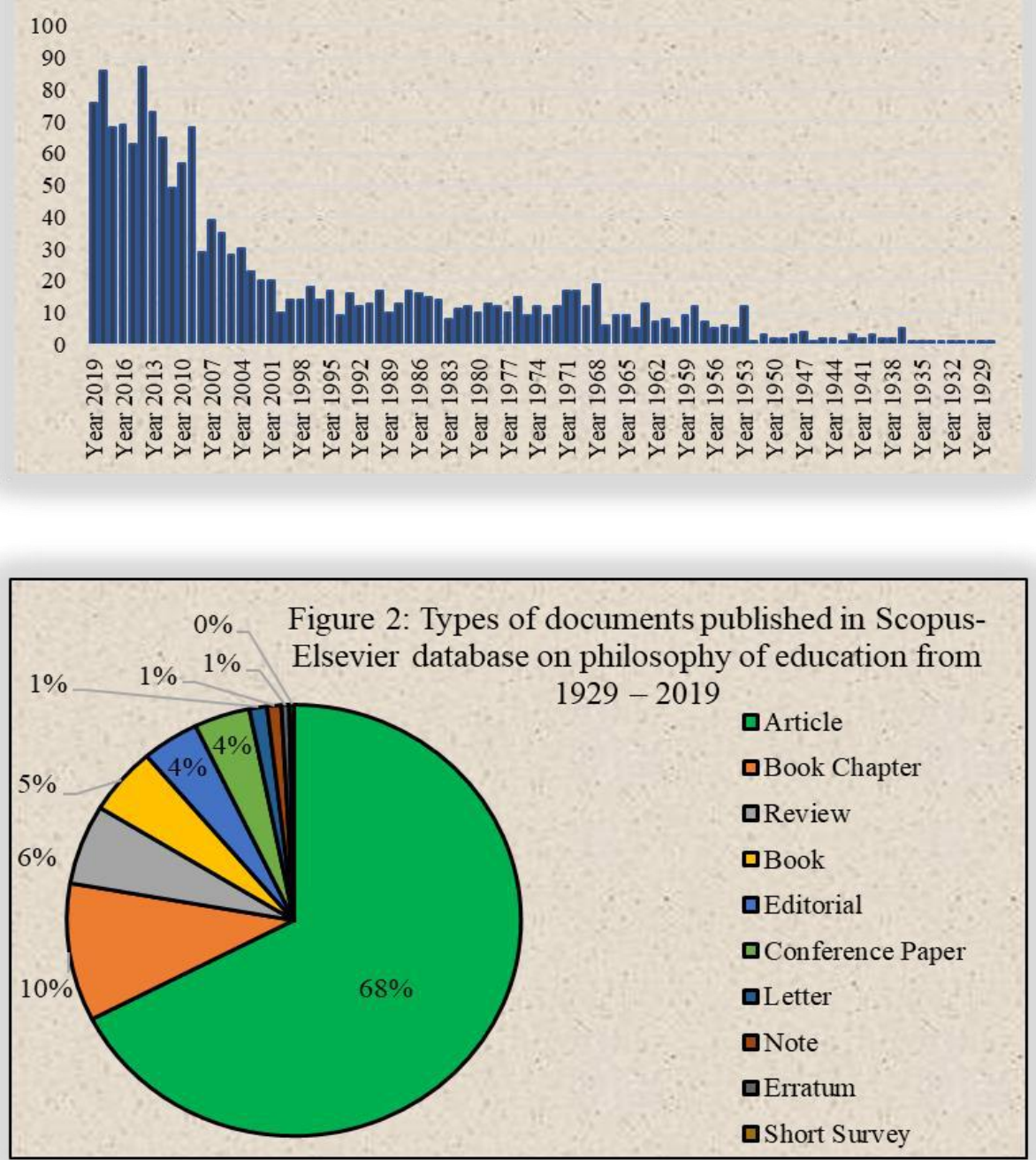

Table 1: Documents published in Scopus-Elsevier database on philosophy of education from 1929 - 2019.

\begin{tabular}{|c|c|c|c|c|c|c|c|c|c|c|c|}
\hline $\begin{array}{l}\text { S. } \\
\text { No }\end{array}$ & Documents & 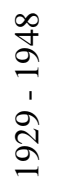 & $\begin{array}{l}8 \\
ٌ \\
\frac{1}{2} \\
\cong\end{array}$ & $\begin{array}{l}\stackrel{2}{\circ} \\
\frac{1}{1} \\
\frac{0}{0}\end{array}$ & 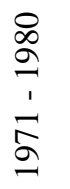 & $\begin{array}{l}\stackrel{2}{\circ} \\
\stackrel{1}{1} \\
\dot{1} \\
\stackrel{2}{2}\end{array}$ & 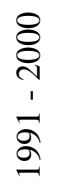 & 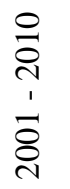 & 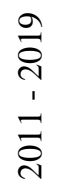 & $\stackrel{\vec{J}}{0}$ & se \\
\hline 1 & Article & 40 & 64 & 91 & 111 & 125 & 119 & 169 & 351 & 1070 & $67.4 \%$ \\
\hline 2 & Book & & & & & & & 26 & 54 & 80 & $5 \%$ \\
\hline 3 & Book Chapter & & & & & & & 47 & 117 & 164 & $10.3 \%$ \\
\hline 4 & Conference Paper & & & 1 & 1 & 3 & 4 & 24 & 30 & 63 & $4 \%$ \\
\hline 5 & Editorial & 3 & & & 1 & 2 & 2 & 33 & 24 & 65 & $4.1 \%$ \\
\hline
\end{tabular}




\begin{tabular}{|r|l|r|r|r|r|r|r|r|r|r|r|}
\hline 6 & Erratum & & & & & & & 1 & 8 & 9 & $0.5 \%$ \\
\hline 7 & Letter & & & 13 & 2 & & & 2 & 3 & 20 & $1.2 \%$ \\
\hline 8 & Note & & & & 1 & & 2 & 5 & 8 & 16 & $1 \%$ \\
\hline 9 & Review & & 1 & & 3 & 3 & 7 & 41 & 40 & 95 & $6 \%$ \\
\hline 10 & Short Survey & & & & & & 3 & 1 & 1 & 5 & $0.3 \%$ \\
\hline \multicolumn{2}{r}{ Total documents } & 43 & 65 & 105 & 119 & 133 & 137 & 349 & 636 & \multicolumn{2}{|c|}{1587} \\
\hline
\end{tabular}

Figure 3 is the essence of the philosophy of research literature; it designs to understand. John Dewey compiles library classification schemes in ten basic classes with thousands of branches and their sub-branches. We set this data according to four main categories of the DDC scheme.
Results show that the writings associated with Social Sciences on top slots trailed by Science, Computer Science, Information and General Work with Philosophy and Psychology as main classes.

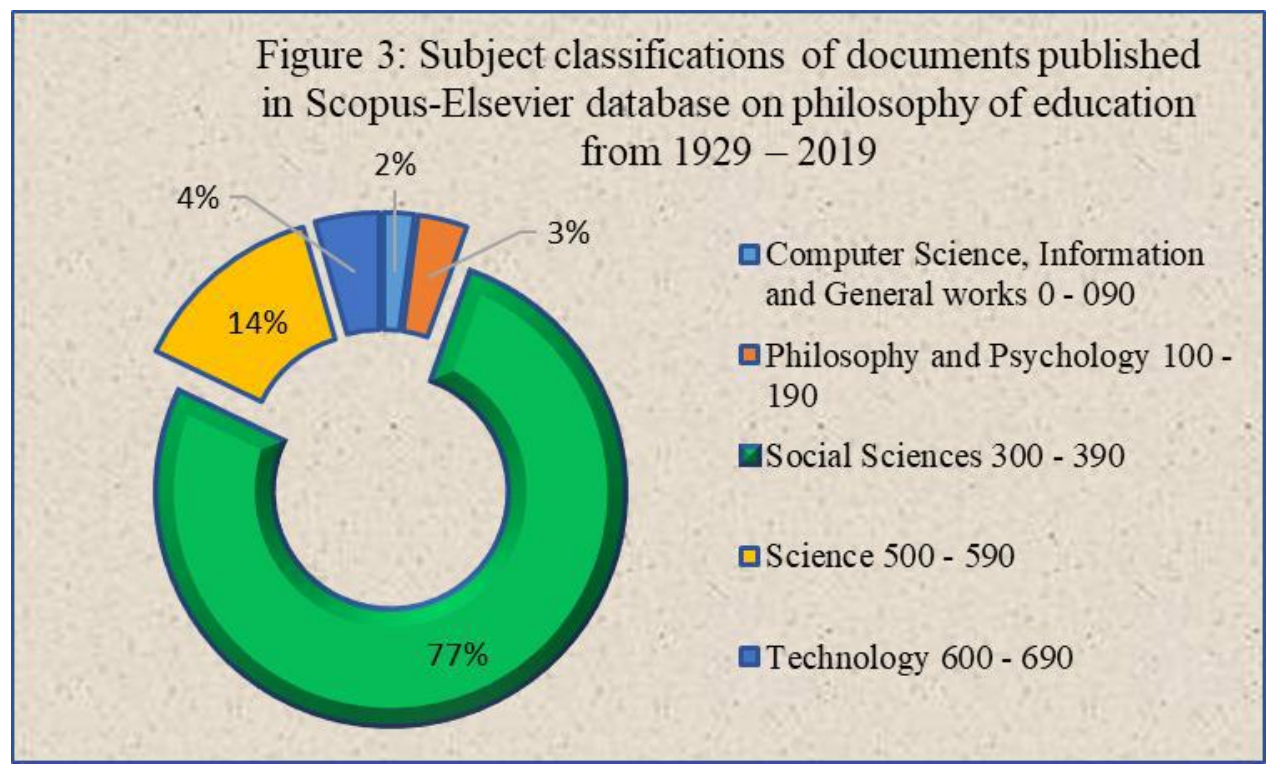

Figure 1 and Table 2 explains the interest of scholar in manuscripts to write. The single or solo author intended to say, share and convince authors on and about the same sky.
In this study, the participation of single-author $75 \%$ is mammoth, followed by two authors as in collaborative manners. 
Figure 4: Pattern of authorship in documents published in Scopus-Elsevier database on philosophy of education from $1929-2019$

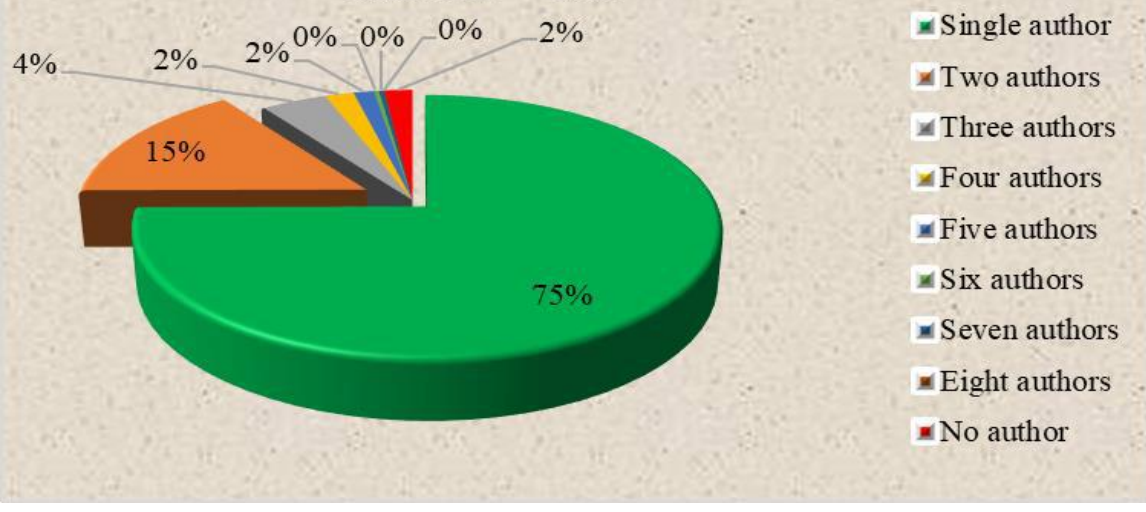

Table 2: Pattern of authorship in documents published in Scopus-Elsevier database on philosophy of education from 19292019.

\begin{tabular}{|c|c|c|c|c|c|c|c|c|c|c|c|c|}
\hline $\begin{array}{c}\text { S. } \\
\text { No }\end{array}$ & Authors & 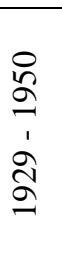 & 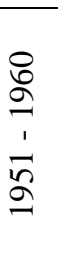 & $\begin{array}{l}\stackrel{0}{2} \\
2 \\
\frac{1}{2} \\
2\end{array}$ & $\begin{array}{l}\stackrel{0}{\infty} \\
\text { a } \\
1 \\
\frac{1}{5}\end{array}$ & $\frac{\stackrel{8}{\circ}}{\frac{1}{2}}$ & 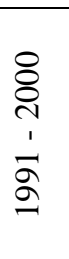 & 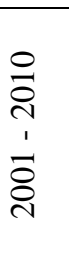 & 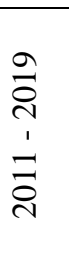 & $\frac{\mathscr{0}}{\stackrel{0}{\Xi}}$ & 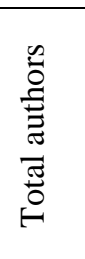 & 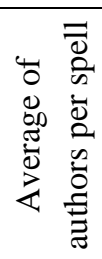 \\
\hline 1 & Single author & 37 & 61 & 95 & 94 & 111 & 104 & 264 & 423 & 1189 & 1189 & 148.6 \\
\hline 2 & Two authors & 3 & 2 & 7 & 14 & 15 & 18 & 47 & 136 & 242 & 484 & 30.2 \\
\hline 3 & Three authors & & & 1 & 1 & 3 & 11 & 15 & 36 & 67 & 201 & 11.1 \\
\hline 4 & Four authors & & & & 1 & 1 & 3 & 7 & 17 & 29 & 116 & 5.8 \\
\hline 5 & Five authors & & 1 & & & 1 & 1 & 6 & 12 & 21 & 105 & 4.2 \\
\hline 6 & Six authors & & & & & & & 2 & 3 & 5 & 30 & 2.5 \\
\hline 7 & Seven authors & & & & 1 & & & 3 & 1 & 5 & 35 & 1.6 \\
\hline 8 & Eight authors & & & & & & & & 1 & 1 & 8 & 1 \\
\hline 9 & No author & 3 & 1 & 2 & 8 & 2 & & 5 & 7 & 28 & 0 & 4 \\
\hline & Total & 43 & 65 & 105 & 119 & 133 & 137 & 349 & 636 & 1587 & 2168 & \\
\hline
\end{tabular}

Table 3 explains 1587 documents published in 697 places, a maximum of $113 ; 7.1 \%$ in one journal and a minimum of 1 in $505 ; 31.8 \%$. It is also revealing that the 11 journals published 518; $32.6 \%$ documents out of 1587 documents. Remaining 1069; 67.3\% documents published by 686 producers. 
Table 3: Documents published in journals indexed in Scopus-Elsevier database on philosophy of education from 1929-2019.

\begin{tabular}{|r|l|r|r|}
\hline & Name of journals & Documents & \multicolumn{1}{l|}{$\%$} \\
\hline 1 & Educational Theory & 113 & $7.1 \%$ \\
\hline 2 & Educational Philosophy and Theory & 103 & $6.4 \%$ \\
\hline 3 & Journal of Philosophy of Education & 92 & $5.8 \%$ \\
\hline 4 & Studies in Philosophy and Education & 75 & $4.7 \%$ \\
\hline 5 & Science and Education & 21 & $1.3 \%$ \\
\hline 6 & Educational Forum & 20 & $1.2 \%$ \\
\hline 7 & Religious Education & 20 & $1.2 \%$ \\
\hline 8 & Peabody Journal of Education & 14 & $0.8 \%$ \\
\hline 9 & Proceedings - Frontiers in Education Conference, FIE & 13 & $0.8 \%$ \\
\hline 10 & 03 Journals published 12 documents & 36 & $2.2 \%$ \\
\hline 11 & Interchange & 11 & $0.6 \%$ \\
\hline 12 & 03 Journals published 10 documents & 30 & $1.8 \%$ \\
\hline 13 & 02 Journals published 09 documents & 18 & $1.1 \%$ \\
\hline 14 & 05 Journals published 08 documents & 40 & $2.5 \%$ \\
\hline 15 & 03 Journals published 07 documents & 21 & $1.3 \%$ \\
\hline 16 & 08 Journals published 06 documents & 48 & $3 \%$ \\
\hline 17 & 06 Journals published 05 documents & 30 & $1.8 \%$ \\
\hline 18 & 18 Journals published 04 documents & 72 & $4.5 \%$ \\
\hline 19 & 37 Journals published 03 documents & 111 & $7 \%$ \\
\hline 20 & 97 Journals published 02 documents & 505 & $31.8 \%$ \\
\hline 21 & 505 Documents published in 505 different places & 1587 & \\
\hline & & $2.2 \%$ \\
\hline
\end{tabular}

Figure 4 highlighted the value of educational philosophy; the association of 68 countries reveals that education is a fundamental source of inspiration, motivation, and encouragement to facilitate any society on the way to science, technology, and mannerism. The 22 countries were mesmerizing that they produced $1445 ; 91 \%$ of research out of 1587 documents, remaining 142; 9\% of documents produced by 46 countries. The United States of America as a nation made 589; 37.1\%, documents, and the United Kingdom 318; 20\%, Canada 80; 5\%, and Australia 76; $4.7 \%$ present in this study on top slots, and inspiring others in a motivational way with sensational word of the philosophy of education.
The other participatory names of hidden countries are Hong Kong, Iran, and Turkey stake with seven documents. India, Norway, Slovakia, Switzerland, Taiwan, and Ukraine shared six articles each. Croatia, Czech Republic, Greece, Indonesia, and Italy support in writings with five documents. Argentina, Lithuania, Malta, Mexico, Poland, and Singapore participated in four articles. Nigeria and Portugal presented the three papers as a country. Colombia, Cyprus, Hungary, Romania, Slovenia, and South Korea submit two papers. Austria, Bangladesh, Belarus, Botswana, Chile, Egypt, Jamaica, Kazakhstan, Kenya, Lebanon, Lesotho, Luxembourg, Pakistan, Philippines, Puerto Rico, Trinidad and Tobago, Uruguay, and Venezuela present their contribution with one document. 
Table 4: The participation and contribution of countries in documents on philosophy of education, published in journals indexed in Scopus-Elsevier database from 1929 - 2019.

\begin{tabular}{|c|c|c|c|}
\hline S. No & Name of country & Documents & $\%$ \\
\hline 1 & United States of America & 589 & $37.11 \%$ \\
\hline 2 & United Kingdom & 318 & $20.04 \%$ \\
\hline 3 & Canada & 80 & $5.04 \%$ \\
\hline 4 & Australia & 76 & $4.79 \%$ \\
\hline 5 & Germany & 53 & $3.34 \%$ \\
\hline 6 & South Africa & 37 & $2.33 \%$ \\
\hline 7 & New Zealand & 32 & $2.02 \%$ \\
\hline 8 & Book Chapter & 27 & $1.70 \%$ \\
\hline 9 & Israel & 27 & $1.70 \%$ \\
\hline 10 & China & 22 & $1.39 \%$ \\
\hline 11 & Ireland & 21 & $1.32 \%$ \\
\hline 12 & Russian Federation & 19 & $1.20 \%$ \\
\hline 13 & Japan & 18 & $1.13 \%$ \\
\hline 14 & Spain & 18 & $1.13 \%$ \\
\hline 15 & Brazil & 17 & $1.07 \%$ \\
\hline 16 & Belgium & 16 & $1.01 \%$ \\
\hline 17 & Denmark & 16 & $1.01 \%$ \\
\hline 18 & Malaysia & 14 & $0.88 \%$ \\
\hline 19 & Netherlands & 14 & $0.88 \%$ \\
\hline 20 & France & 12 & $0.76 \%$ \\
\hline 21 & Sweden & 11 & $0.69 \%$ \\
\hline 22 & Finland & 8 & $0.50 \%$ \\
\hline 23 & 03 Countries participate with 07 articles & 21 & $1.32 \%$ \\
\hline 24 & 06 Countries participate with 06 articles & 36 & $2.27 \%$ \\
\hline 25 & 05 Countries participate with 05 articles & 25 & $1.58 \%$ \\
\hline 26 & 06 Countries participate with 04 articles & 24 & $1.51 \%$ \\
\hline 27 & 02 Countries participate with 03 articles & 6 & $0.38 \%$ \\
\hline 28 & 06 Countries participate with 02 articles & 12 & $0.76 \%$ \\
\hline \multirow[t]{2}{*}{29} & 18 Countries participate with 01 article & 18 & $1.13 \%$ \\
\hline & Total 68 countries & 1587 & \\
\hline
\end{tabular}




\section{DISCUSSION \& CONCLUSION}

According to Dewey Decimal Scheme (DDC), the word philosophy pertained in Philosophy and Psychology as numerical $100-190$. This study specifies that $77 \%$ of the literature published in Social Sciences 300 - 390, followed by Science $500-590,14$ percent. Meanwhile, ten types of documents indicate that most $985,60 \%$ of records published in the last two spells. It is also interesting that 520; $48.5 \%$ articles published in these spells out of 1070 articles, the remaining 550, 51.4\% articles produced in six spells. In the last spell, 636 documents published, one document published on every fifth day, instead of one article created on every ninth day of the last spell.

Every document has a writer. This study reveals that 1189 , $75 \%$ of the solo or single author's documents written out of the 1587 document. A total of 697 journals and publishers provide spaces for publishing these documents, interestingly 518; 32.6\% documents published in 13 places, 564; 35.5\% documents got spaces from 179 locations, and 505; $31.8 \%$ documents produced by 505 sites out of 697 places. Total 68 countries contributed 1587 documents, 22 countries out of 68 produced 1445; $91 \%$ documents and 46 states had credit $142 ; 9 \%$ documents. This study highlighted that education is not a simple work to think, plan, and execute. Every thought, subject, the discipline required the mode of communications to explain the terminology of actions. In conclusion, the study found that abilities and instinct of human polished by education, and this spiritual substance work as a medium to rethink with a philosophical way to contribute individually and society as a whole.

Disclaimer: This data published in Scopus-Elsevier Database indexed journals from 1929 to 31 December 2019, and downloaded 2 July 2020 for estimation.

\section{REFERENCES}

[1] Feldges, T., (2019). Introduction: Philosophy and education. Philosophy and the Study of Education: New Perspectives on a Complex Relationship, pp. 1-12. DOI: 10.4324/9780429506536-1

[2] Gereluk, D., (2019). A problems-based approach in philosophy of education. The Importance of Philosophy in Teacher Education: Mapping the Decline and its Consequences, pp. 105-120. DOI: 10.4324/9780429426827-7

[3] Hallinger, P., Wang, R., Chatpinyakoop, C., Nguyen, V.-T., Nguyen, U.-P., (2020). A bibliometric review of research on simulations and serious games used in educating for sustainability, 1997-2019. Journal of Cleaner Production, 256, p.120358. https://doi.org/10.1016/j.jclepro.2020.120358

[4] Jun, A., Collins, C.S., (2019). Philosophy, culture, and the battle against mission drift in higher education in Asia. Education in the Asia-Pacific Region, 49, pp. 151-158. DOI: 10.1007/978-981-13-6532-4_12

[5] Kizel, A., (2019). Philosophy with children and selfdetermination in education. Philosophy and the Study of Education: New Perspectives on a Complex Relationship, pp. 28-40. DOI: $\underline{10.4324 / 9780429506536-3}$

[6] Lanford, M., (2020). Long-term Sustainability in Global Higher Education Partnerships. In Successful Global Collaborations in Higher Education Institutions, pp. 87-93. https://www.tandfonline.com/doi/abs/10.1080/14783363.201 7.1422710

[7] Li, J., Lei, L., \& Cheng, L., (2020). Mapping evaluation, appraisal and stance in discourse (2000-2015): A bibliometric analysis. Glottotheory, 10(1-2), 31-55. https://doi.org/10.1515/glot-2019-0002

[8] Mustapha, O. A., Teriba, E. E., Ezekiel, O. S., Olude, A. M., Akinloye, A. K., \& Olopade, J. O., (2020). A study of scientific publications on the greater cane rat (Thryonomys swinderianus, Temminck 1827). Animal Models and Experimental Medicine, 3(1), 40-46. https://doi.org/10.1002/ame2.12103

[9] Opaleke, J. S., (1998). Effect of the user education programme on undergraduate students' library exploration at the University of Ilorin. The International Information \& Library Review, 30(4), 275-287. https://doi.org/10.1006/iilr.1998.0092

[10] Smeyers, P., Depaepe, M., (2020). The Research Community Philosophy and History of the Discipline of Education: A Retrospect of Collaborative Research over Two Decades. Journal of Philosophy of Education, 54 (3), pp. 645-654. DOI: $\underline{10.1111 / 1467-9752.12439}$

[11] Sulaeman, S., Rijal, M., Malawat, M. and Sere, I., (2020). The symbolic communication of the ukuwala mahiate ritual of the indigenous peoples of Mamala, Moluccas, Indonesia. Journal of International Migration and Integration, pp.1-19. https://link.springer.com/article/10.1007/s12134019-00753-1

[12] Tan, M.Y., (2020). The Personal Experience: Blogging as Development of Spiritual Identity. In Malaysian Christians Online, pp. 51-81. Springer, Singapore. https://link.springer.com/chapter/10.1007/978-981-15-2833$\underline{03}$

[13] Thomas, A.M., (2018). Adam Smith on the philosophy and provision of education. Journal of Interdisciplinary Economics, 30(1), https://doi.org/10.1177/0260107917728597 